\title{
THE USE OF COOPERATIVE INSTRUCTIONAL STRATEGIES TO CATER FOR THE LEARNING STYLE DIFFERENCES AMONG HIGH SCHOOL SCIENCE LEARNERS
}

\author{
Sakyiwaa Danso $^{1 *}$ and Emmanuel Mushayikwa ${ }^{1}$ \\ ${ }^{1}$ University of the Witwatersrand, South Africa
}

\begin{abstract}
The continuous use of the traditional method of teaching physical sciences in most senior secondary schools in South Africa and in particular schools in OR Tambo Inland District has contributed to the underperformance of learners in the subject. This has called for a shift from teacher-centered to a progressive learner-centered approach based on inclusiveness and collective learning to encourage diversity of reception and information processing. Therefore, this study investigated the use of Cooperative Instructional Strategy, considering learners learning style preferences to enhance learner's achievement in electricity and magnetism. A pragmatic Mixedmethods sequential design was adopted for the study. The choice of mixed methodology was meant for both methods to complement each other for the purpose of data triangulation. Purposive sampling technique was used to select two high schools within the OR Tambo Inland District of Mthatha. Learning style questionnaire, physical sciences achievement test, interview, and observation schedules were the main instruments used to collect data. The quantitative data were analysed descriptively, while the qualitative aspect was analysed through thematic content analysis. It was found that cooperative instructional strategies improved learners' performance in physical sciences. It is therefore recommended that teachers utilise appropriate instructional strategies that cater for all the differences learners bring to the classroom for effective teaching and learning to take.
\end{abstract}

Keywords: Academic Achievement, Cooperative Instructions, Electricity, and Magnetism, Physical Sciences

\section{Introduction}

According to the Department of Basic Education (DBE, 2011), Physical Sciences promotes knowledge and skills in scientific inquiry and problem-solving; the construction and application of scientific and technological knowledge; and an understanding of the nature of science and its relationships to technology, society, and the environment. Despite the importance of physical sciences education to the development of the nation, the related literature (for example Karacop, 2017) shows that learners at all levels of the educational ladder have difficulty in learning physical science and have developed a negative attitude towards the subject. These and other similar learning difficulties revealed in the previous studies may occur due to so many factors. Some studies (for example, Mashile, 2001; Mji \&Makgato, 2006) in South Africa have investigated and reported on different factors that particularly affect the teaching and learning of physical sciences. These include; poor teaching strategies, lack of basic content knowledge of teachers and mismatches of teachers' teaching styles and learners' learning styles, among others. In their conclusion, they indicated that the recurring poor performance in the subject calls for a concerted effort for measures that will help improve the status quo.

According to Amedu and Gudi (2017), no one teaching method is suitable for the realisation of all teaching goals and outcomes. However research reports point to the importance of cooperation, collaboration, discussion, learning style-based instructions, verbal interaction and group work (De Baz, 2001; Doymus, 2008; Akimbobola, 2015, Gocer, 2010) in the teaching-learning process. Therefore, to enhance the understanding of learners in physical sciences, learners must be more active in the classroom and must creatively acquire 
knowledge, especially in understanding and solving science problems and be given the opportunity to develop, to interact, and to share with friends through a cooperative learning activity. However, Zakaria and Iksan (2007) argued that in cooperative learning, learners work face to face to complete a given task collectively. Cooperative learning also encourages learners to interact and to communicate with peers in harmony. In this way, cooperative learning promotes values such as honesty, cooperation, mutual respect, responsibility, tolerance, and willing to sacrifice a consensus. Execution of duties in cooperative learning could, therefore, develop self-confidence in learners. Similarly, Shimazoe and Al-drich (2010) affirmed the argument put forward by Zakaria and Iksan (2007) and showed that cooperative learning promotes deep learning of materials and helps learners to achieve better grades and hence, Melihan and Sirri (2011) concluded in their study that cooperative learning method is more effective than the traditional teaching method in the academic success of learners.

In general, cooperative learning is considered to have positive effects on the academic achievement of learners, the development of social skills, the personality traits and psychological variables (Karacop, 2017).

However, research has mostly focused on which applications of cooperative learning are effective on variables and to what extent, and in which circumstances these effects are valid. Thus, different in-class applications of cooperative learning have emerged and these different cooperative learning methods and techniques are applied at various levels of education all over the world and in different subject areas. Yet, research studies still seek for the ways to enhance the effectiveness of these methods and to develop more effective in-class practices (Huang, Liao, Huang, Chen, 2014; Slavin, 2015). Jigsaw method-based, one of the techniques which are used in the implementation of cooperative learning brings the cooperation to the forefront by providing support to learners' working together and removing competition in the classroom.

Against this background, this study investigated the use of Jigsaw method-based cooperative instructional strategy to cater for the learners learning style differences in the science classroom to improve their performance in the subject.

\section{Statement of the Problem and Research Questions}

Electricity and Magnetism are pivotal concepts that play central roles in science. Nevertheless, these are also concepts that give learners difficulties. Most learners do not have interest in the study of electricity and magnetism. They perceived the concept to be very difficult and too abstract to comprehend and hence resulting in poor performance among learners in physical sciences. This is often blamed on the use of the traditional teaching method in schools and classes which do not accommodate all learners equally. Therefore, this study aimed to overcome this problem by using Jigsaw Method-Based Cooperative Instructional Strategies (JMBCIS) as an instructional tool in the science classroom, considering learners learning style preferences to enhance Grade 11 learners' achievement in electricity and magnetism.

The following research questions were raised for answering:

1. What are the effects of using Jigsaw Method-Based Cooperative Instructional Strategy to teach electricity and magnetism in the physical sciences classroom?

2. How would the performance in electricity and magnetism differ between learners taught using Jigsaw Method-Based Cooperative Instructional Strategy and learners taught using traditional teaching strategy?

3. How would the levels of interest and motivation in electricity and magnetism differ between learners taught using Jigsaw Method-Based Cooperative Instructional Strategy and learners taught using traditional teaching strategy? 


\section{Hypothesis}

$\mathrm{H}_{0}$ : There is no significant difference in physical science achievement between learners who were exposed to Jigsaw Method-Based Cooperative Learning and those who were exposed to traditional teacher-centered instructional strategy.

\section{The literature survey and the theoretical foundation}

The theoretical framework underpinning this study is Vygotsky's (1978) sociocultural theory. Sociocultural theory is a theory of the development of higher mental practices which regards social interaction as the core of teaching and learning process (Behroozizad, Nambiar \& Amir, 2014). Therefore, it was important to use sociocultural theory as a framework for meaningful verbal interactions with others in the classroom as a social context which brings about complex and higher mental functions among learners (Lantolf, Thorne, \&Poehner 2015).

From Vygotsky's perspective, the concept of the Zone of Proximal Development (ZPD) helps a child's interaction with an adult or more capable peer awakens mental functions that have not yet matured and thus lie in the region between actual and potential developmental levels. The Zone of Proximal Development is, therefore "the distance between the actual developmental levels as determined by independent problem solving and the level of potential development as determined through problem-solving under adult guidance or in collaboration with more knowledgeable peers" (Vygotsky, 1978, p. 86). For that reason, the social environment is a crucial element which supports the child culturally to adapt to new situations when needed. Thus, an instructional implication informed by a sociocultural perspective is thought to occur through interaction, negotiation, and collaboration. These features are characteristic of "cooperative learning".

Jigsaw Method-Based Cooperative Instructional Strategy was originally developed by Aronson and Colleagues in 1978 (Sarah \& Cassidy, 2006). This instructional strategy requires learners to work in groups of five to six members. Each learner in a group is given information to which no one else in the group has access, thus making each learner "expert" on his or her section of the subject matter. After receiving their assignments, each team member reads a section. Next, members of different teams who have studied the same sections meet in "expert groups" to discuss their sections. Then the learners return to their original teams and take a turn teaching their teammates what they have learnt. All learners in a group are expected to learn all the subject matter assigned to members of their group. After instruction in Jigsaw Method-Based Cooperative Learning, teachers test learners individually and produce team scores based on each learner's test performance according to Bukunola and Idowu (2012).

Nevertheless, Nurhuda, Lukito, and Masriyah (2018) investigated the effectiveness of cooperative learning instructional tools with a predict-observe-explain strategy on the topic of cuboid and cube volume. They found that learners learning outcomes in the experimental class using cooperative

Learning was better than the results of the learners learning in the control class. They, therefore, concluded that cooperative learning with predict-observe-explain strategy was effectively used in teaching the topic of cube and cuboid volume. Similarly, Brad (2000) investigated the effectiveness of cooperative learning on learners' academic performance in computer science under cooperative and teacher-centered learning environments. $\mathrm{He}$ found that learners in cooperative learning group exhibited a higher level of academic performance than learners in the traditional teacher-centred group. Cooperative learning has also been reported to produce a range of positive social, affective and psychological outcomes, including social support, the quality of learner relationships, attitude to learning skills and self-esteem (Van Dat \& Ramon, 2012). According to Parr (2007), one of the main benefits of cooperative learning is that it can foster an environment that embraces the great diversity of learners that are found in today's classrooms. This viewpoint is shared by Lord (2001) who claims that cooperative learning allows learners to share their differences in a positive way and can add value to the 
team by bringing their different backgrounds to the group. Shimazoe and Aldrich (2010) provide several benefits of the use of cooperative learning in the classroom. They specified that cooperative learning promotes deep learning of materials. In addition, learners achieve better grades in their subjects. Furthermore, learners learn social skills and civic values, higher-order, and critical thinking skills. Cooperative learning also promotes personal growth and develops positive attitudes towards learning as affirmed by Bilesami and Oludipe (2012).

\section{Methodology}

This study employed a pragmatic sequential explanatory mixed method design in order to find the relationship between Jigsaw method-based cooperative learning and teacher-centered instructional strategy with regards to learners' achievement. According to Morgan (2007), pragmatism provides a philosophical basis for researchers who use mixed methods; therefore, the use of both quantitative and qualitative assumptions to engage in their research. The quantitative phase of the study employed a quasi-experimental design consisting of the treatment group and a control group since the classes existed as intact groups. Specifically, the nonrandomized pre-testpost-test design was used. This design is often used in classroom experiments where experimental and control groups are in their natural classroom setting which cannot be disrupted for the research purposes (Abdisa \& Getinet, 2012). In quasi-experiments, the cause could be manipulated and occurs before the effect is measured (Shadish, Cook, \& Campbell, 2002). However, quasi-experimental design features usually create less compelling support for counterfactual inferences. For example, quasi-experimental control groups may differ from the treatment condition in many systematic (non-random) ways other than the presence of the treatment.

In quasi-experiments, the researcher has to enumerate alternative explanations one by one, decide which are plausible, and then use logic, design, and measurement to assess whether each one is operating in a way that might explain any observed effect (Shadish, et al., 2002). The difficulties are that these alternative explanations are never completely enumerable in advance, that some of them are particular to the context being studied, and that the methods needed to eliminate them from contention will vary from alternative to alternative and from study to study. Hence, intact class groups, which are normally non-equivalent, were selected and later these groups were equated by applying appropriate statistical techniques. The design is given below.

Table 1: The design for the Experimental and Control groups

\begin{tabular}{|c|c|c|c|}
\hline GROUPS & PRE-TEST & TREATMENT & POST-TEST \\
\hline EXPERIMENTAL & $\mathrm{O}_{1}$ & $\mathrm{X}$ & $\mathrm{O}_{2}$ \\
\hline CONTROL & $\mathrm{O}_{3}$ & -- & $\mathrm{O}_{4}$ \\
\hline
\end{tabular}

Where:

$\mathrm{X}$ - Exposure of a group to an experimental condition (treatment).

----- Exposure of a group to a control condition (No treatment).

$\mathrm{O}-\mathrm{Text}$ measure

$\mathrm{O}_{1}$ and $\mathrm{O}_{2}-$ Pre-test

$\mathrm{O}_{2}$ and $\mathrm{O}_{4}-$ Post-test

Hence, the study purposefully sampled two schools which were randomly assigned to an experimental and a control group, consisting of 43 learners in the experimental group and 46 learners in the control group. The experimental group was exposed to Jigsaw method-based cooperative instructional strategies, while the control group was exposed to the traditional teacher-centered instructional strategies. Three-day training was organized for the teacher in the experimental group on how to implement Jigsaw method-based cooperative instructional 
strategy. The intervention lasted for six weeks during which the topic electricity and magnetism were taught in both the experimental group and the control group. In order to collect data for the study, the following instruments were developed, standardised and used:

- Physical Science Achievement Test (PSAT) - Pre-test and Post-test.

- Structured interview.

- Observation schedules.

Before the main study could be conducted, a pilot study was undertaken to trial test the research instruments and the criteria, and refine them for the main study. A further purpose of this Pilot study was to obtain some preliminary data to investigate the feasibility of the planned project to bring possible deficiencies in the measuring procedure to the fore, as observed by Huysamen (1993).

The sample used as a pilot in this study comprised of one Grade 11 physical sciences class from the researcher's school. The sample comprised 30 Grade 11 learners. This school is also located in the same circuit as the two sampled schools for the main study in Mthatha District. This school shared similar characteristics with the sampled schools. The researcher also had the same experience as the teachers from the sampled school. The researcher was motivated to pilot the study in his school in order to experience the use of the cooperative instructional strategy first hand to provide constructive findings to the study.

\section{Reliability and Validity}

The study worked towards reliability and validity in different ways. The study employed direct classroom observation which enabled the researchers to spend reasonable time observing the sampled teachers deliver lessons in their natural settings. This contributed significantly to the credibility of the observation process.

Interview transcripts were carefully transcribed, the codes were compared and finally, the core codes were selected and used in the analysis of the findings. In addition, direct quotes from the learners were used to support the themes that emerged during data analysis.

The Physical Science Achievement Test (PSAT) was prepared by the researchers and developed with proper weighting of the objectives, content area and difficulty level to ensure that the task provides an opportunity for learners to achieve at various cognitive levels. The test was given to experts to see whether the items correspond to what the researchers intend to be covered by the test. Reliability of the test was established by Test-Retest method. The retest was administered after an interval of three weeks. The correlation between the first set of scores and the second set of scores was determined. The marks yielded a Spearman reliability coefficient of 0.79 which was seen as excellent.

\section{Data collection procedures and Analysis}

The study commenced with the administration of learning style questionnaire instrument to identify learners learning style profiles. This was followed by the administration of a pre-test. The main essence of the pre-test was to establish the equality of the two groups. Immediately after the pre-test was conducted, the researcher and the two participating teachers met for two hours. At that meeting, subtopics to be taught under electricity and magnetism were reviewed and reorganised for the purpose of the research. This took about one hour after which the teacher for the control group left the meeting and the teacher for the experimental group was trained by the researcher on how to use the Jigsaw method-based cooperative instructional strategies. Lesson transcripts were prepared by the researcher and handed over to the participant teacher for use in his lessons.

The intervention proceeded just after the training. In the experimental group, learners were divided into groups of four members. The decision to form groups of four members according to Asherson (2008) was based on 
research that suggested that groups larger than four presented problems, hence the need for making it easier for unexcited learners to play a smaller role in group activities. The teams were formed based on learners' performance level, ability, sex, and social economic status.

Quantitative data were analysed descriptively. Thematic content analysis framework was employed to analyse qualitative data. The quantitative data were analysed using Microsoft Excel spreadsheets. The results from the PSAT, interviews and classroom observations were triangulated in the next section.

\section{Results and Discussions}

\section{Learners' learning style profiles}

In Table 2 below, learners learning style profiles are illustrated. The Table 2 shows that there are more sensing learners $(74 \%)$ than intuitive learners $(26 \%)$, there are more visual learners $(72 \%)$ than verbal learners $(28 \%)$, there are more sequential learners $(71 \%)$ than global learners $(29 \%)$, and there are more active learners $(70 \%)$ than reflective learners $(30 \%)$ in the total number of learners sampled for the study.

Table 2: Distribution of learning style preferences among the grade 11 science learners

\begin{tabular}{|c|c|c|c|c|c|}
\hline \multirow{2}{*}{\multicolumn{2}{|c|}{$\begin{array}{l}\text { Felder-Silverman Learning Style } \\
\text { Dimensions }\end{array}$}} & \multicolumn{2}{|c|}{$\begin{array}{l}\text { Learners' distribution of learning style } \\
\text { profiles }\end{array}$} & \multicolumn{2}{|c|}{ Total } \\
\hline & & Experimental group & Control group & $\mathrm{n}$ & $\%$ \\
\hline \multirow{3}{*}{ Processing } & Active & 30 & 32 & 62 & 70 \\
\hline & Reflective & 13 & 14 & 27 & 30 \\
\hline & Total & 43 & 46 & 89 & 100 \\
\hline \multirow{3}{*}{ Perception } & Sensing & 36 & 30 & 66 & 74 \\
\hline & Intuitive & 7 & 16 & 23 & 26 \\
\hline & Total & 43 & 46 & 89 & 100 \\
\hline \multirow{3}{*}{ Input } & Visual & 33 & 31 & 64 & 72 \\
\hline & Verbal & 10 & 15 & 25 & 28 \\
\hline & Total & 43 & 46 & 89 & 100 \\
\hline \multirow{3}{*}{ Understanding } & Sequential & 29 & 34 & 63 & 71 \\
\hline & Global & 14 & 12 & 26 & 29 \\
\hline & Total & 43 & 46 & 89 & 100 \\
\hline
\end{tabular}

\section{Results of the pre-test and post-test}

The pre-test scores and the post-test scores were analysed using the descriptive statistics to form the basis of comparison of the experimental group and the control group. 


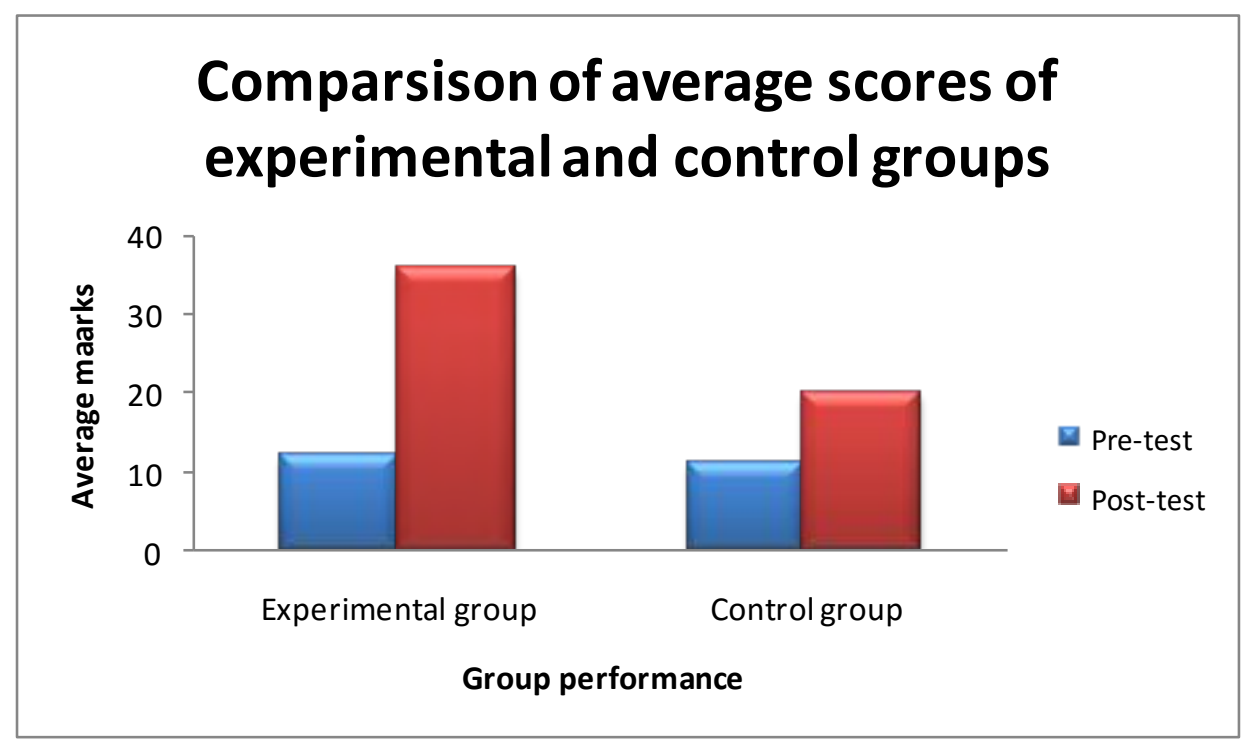

Figure 1: Comparison of average scores of experimental and control groups

From Figure 1, the average marks obtained by the learners in the experimental group in the pre-test and post-test are 12 and 36 respectively. This shows a $2.3 \%$ increase in the average marks after the intervention. Similarly, the average marks obtained by the learners in the control group in the pre-test and post-test are 11 and 20 respectively. This shows a $0.9 \%$ increase in the average marks of the control group. However, the average percent increase in the average marks for the experimental group was far higher than the control group. The data also shows that in the post-test of the experimental group, the mean improved significantly.

\section{Differences in performance of the experimental group}

Figure 2 gives a graphical presentation of the pre-test and post-test scores of the Experimental group.

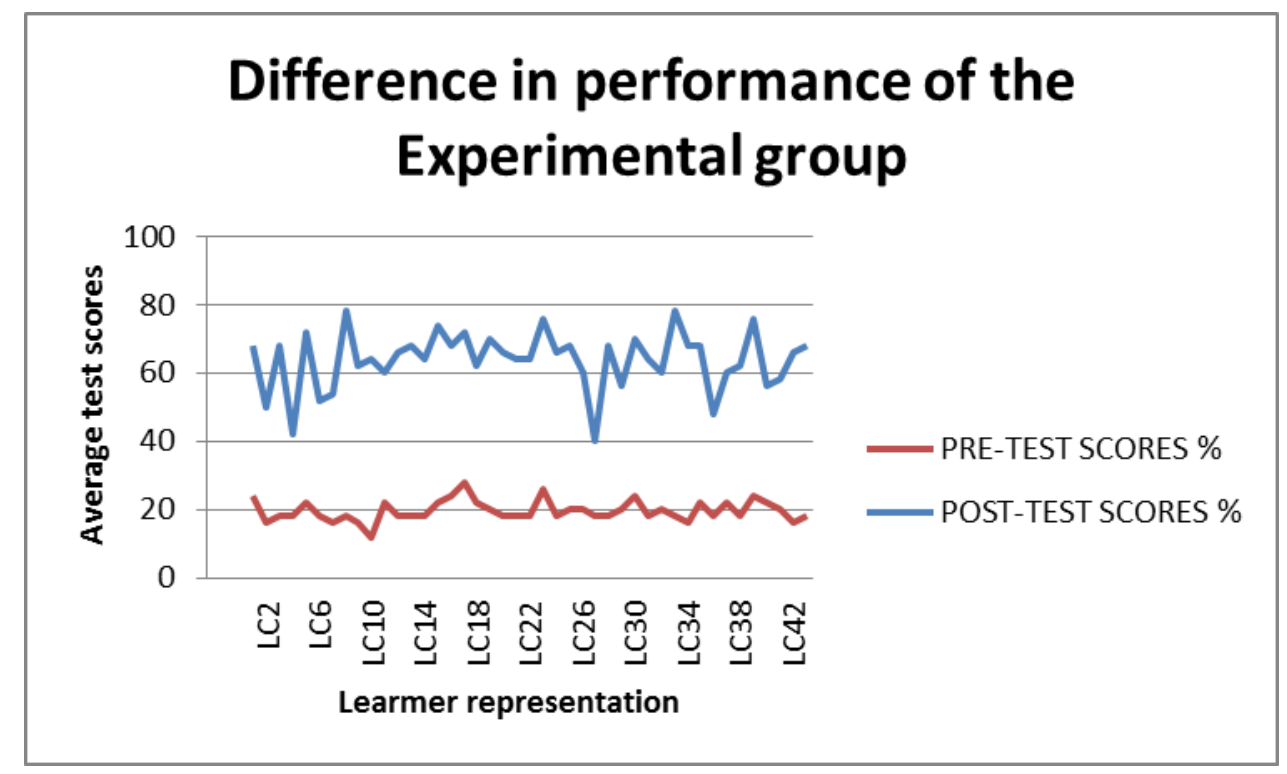

Figure 2: The difference in performance of the Experimental group 
Figure 2 shows the distribution of marks obtained by learners in the experimental group. It is evident from the graph that there is a significant change in marks obtained after the treatment.

In addition, Figure 3 represents the distribution of marks obtained by learners in the control group.

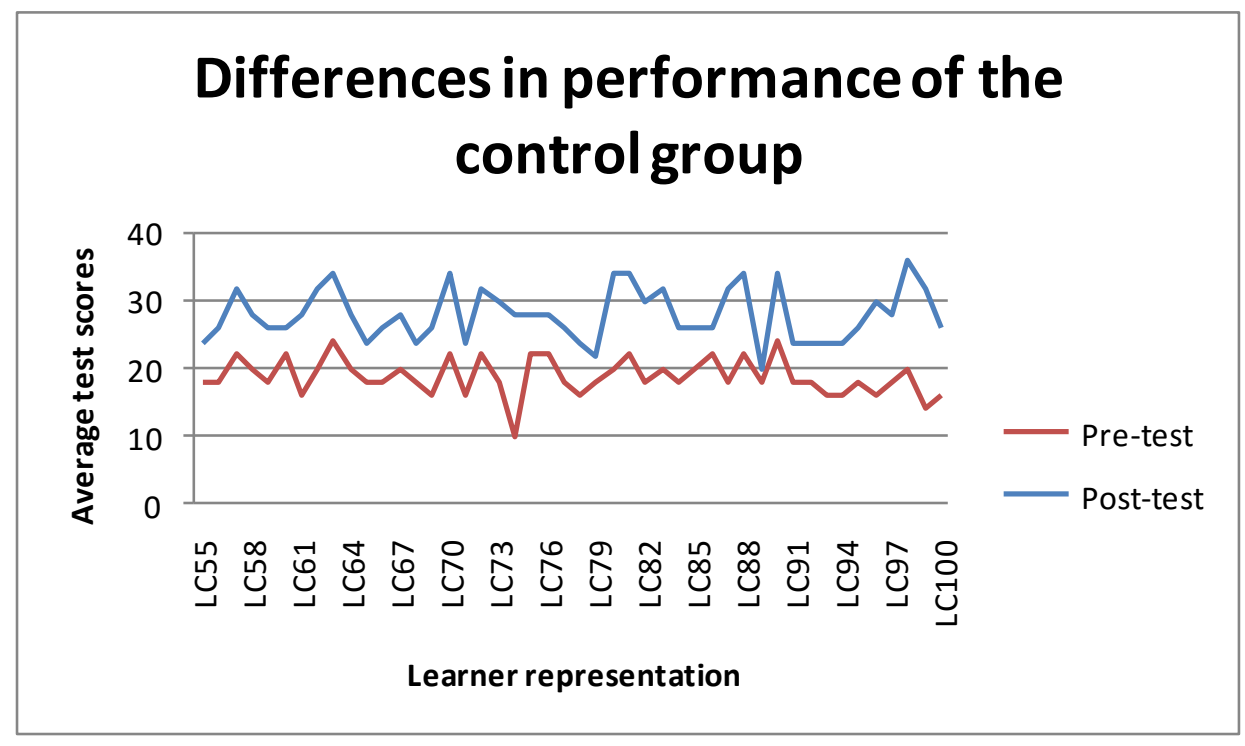

Figure 3: The difference in the achievement of the control group

Figure 3 shows the distribution of marks obtained by learners in the control group in the pre-test and post-test. The Figure shows that although there is a change in marks by the control group, it is not much significant compared to those in the experimental group.

\section{The Relationship between Cooperatives Instructional Strategy, the Tradition Teaching Strategy and Learners' Achievement}

The findings from the test results indicated that both the Jigsaw method-based cooperative instructional strategy and traditional teaching method enhanced performance in physical sciences. However, the post-test scores of the learners showed that Jigsaw method-based cooperative instructional strategy resulted in better performance than a traditional teaching method. The findings support the null hypothesis that there is no significant difference between the pre-test mean scores and the post-test mean scores between the experimental and the control groups. The findings are also in congruence with findings from the literature on the positive impact of cooperative instructions on learner achievement in a wide range of subject fields (see Shimazoe \& Aldrich, 2010; Fengfeng \& Barbara, 2007). In addition, this study is also in line with the study of Karacop (2017) who found that teaching physics in accordance with a Jigsaw method based on cooperative learning revealed a higher level of success than teaching through a teacher centred instructional strategy. Hence, this study offers support to the claim that cooperative instructional strategy promotes academic achievement in sciences.

\section{Learners Experiences with Cooperative Learning}

This study identifies a number of views expressed by learners with regards to the use of cooperative instructional strategy. This study found that cooperative learning was exciting and enjoyable for the learners as they managed to help one another to learn and understand the tasks. More importantly, the study found that learners worked together as a group and never got bored during the lessons. In addition, the study found that cooperative instructional strategy provides harmonious relationship among learners and assist them to perform science tasks with ease. 
Learners improved their relationships with one another in the study of electricity and magnetism. Learners affirmed cooperative learning to be very engaging. They found the idea of assisting one another to complete a learning task which was very engaging according to the learners. This finding concurred with findings of Yang and Zheng (2010), who posit that psychological and social abilities are enhanced through cooperative learning. Some learners narrated:

“Cooperative learning encourages learners to become more active in the classroom"(Ayabonga).

Through active participation, learners' social and communication skills were improved. In most cases, learners indicated that the use of cooperative strategy by their teacher has helped them to achieve more in class. It has increased their attitude toward learning more and helping them to perform better in class. This assertion by learners has been supported by Weinburgh (1995) and Alrayah (2018) that positive attitude towards cooperative learning contributes to greater achievement.

\section{Effect of Cooperative Learning on learner Interest and Motivation}

The study revealed that the use of cooperative instructional strategy encourages intrinsic motivation among learners in the study of electricity and magnetism. More specifically, those who received cooperative instructional strategy displayed a higher sense of efficacy in learning and attached higher task value to their school work than those who received the traditional teaching approach. Cooperative learning also increased learners' interest and motivation in learning physical sciences. This was particularly evident in the sense of commitment and enthusiasm displayed by the learners during the treatment period in particular. These findings also converge with those of the literature, more specifically, with the views by Lan and Skoog (2003) that when learners take initiative for their own learning, they are eventually motivated to learn more, spend more time and effort in studying sciences. This was particularly showed by learners through the sense of commitment displayed during the treatment class. The high level of self-worth displayed by the learners who received the cooperative instructions can be explained in the light of the Vygotsky's (1978) sociocultural theory and the social independence theory (Johnson \& Johnson, 2009). The sociocultural theorist highlights that development depends on interaction with people and the tools that the culture provides to help form their own view of the world (Behroozizad, et al., 2014). Vygotsky contends that "social interaction and cooperation with peers are indispensable factors for inner speech and metacognition to take place" (p. 90). The social interdependence theory also supports the use of cooperative learning as it emphasises positive interdependence or cooperation which encourages and motivates group members to facilitate each other's efforts to learn.

\section{Conclusion}

This section marks the conclusion of the research study in which the research questions formulated were answered, data generated in the study analysed and the aims of the study realised. The improvement in the performance of the experimental group may be strongly attributed to the use of jigsaw method-based cooperative instructional strategy that engaged learners to work in groups, as opposed to the teacher-centred teaching method used for teaching the control group. From the observation of all the lessons and the analysis of both the tests and the interview questions, it can be concluded that the group works captured the attention of the learners, and this view was reflected by the learners in their responses to the interview questions.

Nevertheless, the study found that Jigsaw method-based learning improved learner performance in physical sciences than the teacher-centred based instructional strategy.

\section{Recommendations}

It is recommended that the teacher training programmes in universities should be revised in order to equip new teachers with the required and appropriate knowledge and skills to implement differentiated instructions such as 
cooperative instructional strategies in the teaching of physical sciences effectively in the high schools. Furthermore, a necessity for research interrogating learners cultural background influence on learners learning styles in the design of instructions to facilitate the smooth transfer of knowledge in high schools across South African.

\section{Implications}

Based on the findings of the present study, physical science teachers could consider the effects of a number of cooperative learning methods, such as STAD, TGT, TAI, and CIRC in their instructions. This is due to the fact that increase in instructional strategy use could be attributed to learners' conscious decision-making in the teaching-learning process. Moreover, learners would understand that they must work collectively towards the group goals so that they could succeed as a team. Nevertheless, this postulation was based on the premise that positive interdependence and individual accountability had already existed. Teachers need to be aware that cooperative learning will not be effective without these two elements.

\section{Disclosure statement}

No potential conflict of interest was reported by the authors.

\section{References}

Abdisa, G., and Getinet, T., 2012, The effect of guided discovery on students' Physics achievement. Journal of Physics Education, 4(6), 530-537.

Akinbobola, O.A., 2015, Effects of Learning Styles and Instructional Strategies on Students' Achievement in Nigerian Senior Secondary School Physics. Advances in Physics Theories and Applications, 41 (1).

Alrayah, H., 2018, The Effectiveness of Cooperative Learning Activities in Enhancing EFL Learners' Fluency. English Language Teaching, 11(4), 21

Amedu, O.I., and Gudi, K.C., 2017, Attitude of Students towards Cooperative Learning in Some Selected Secondary Schools in Nasarawa State. Journal of Education and Practice, 8(10), 29-34.

Asherson, C., 2008, Cooperative learning: We instead of me (California State University, Northridge).

Behroozizad, S., Nambiar, R.M., and Amir, Z., 2014, Sociocultural theory as an approach to aid EFL learners. Reading, Matrix 14(2), 217-226.

Bilesanmi, A. J., and Oludipe, D. I., 2012, Effectiveness of cooperative learning strategies on Nigerian secondary school students' academic achievement in basic science. British Journal of Education, Society \& Behavioral Science, 2 (3), 307-325.

Brad, H., 2000, An experiment using teacher-centered-instruction versus student-centered instruction as a means of teaching American government to high school seniors (seniors.www.secondary English.com).

Bukunola, B.A.J.. and Idowu, O.D., 2012, Effectiveness of cooperative learning strategies on Nigerian junior secondary students' academic achievement in basic science. British Journal of Education, Society \& Behavioural Science, 2(3), 307-325.

Department of Education., 2011, National Curriculum Statement Grades R - 12: Curriculum and Assessment Policy (CAPS) Physical Sciences. Pretoria: Department of Education. South Africa.

De- - Baz, T., 2001, The Effectiveness of the Jigsaw Cooperative Learning on Students' achievement and Attitudes towards Science. Science Education international. 12 (4), 6-11.

Doymus, K., 2008, Teaching chemical equilibrium with the jigsaw technique. Research in Science Education, 38(2), 249-260.

Effandi, Z., and Zanaton, I., 2007, Promoting cooperative learning in Science and Mathematics Education: A Malaysian perspective. Eurasia Journal of Mathematics, Science and Technology Education, 3 (1), 35-39. 
Fengfeng, k., and Barbara, G., 2007, Game playing for mathematics learning: Cooperative or Not? British Journal of Education Technology, 38 (2), 249-259.

Göçer, A., 2010, A comparative research on the effectivity of cooperative learning method and jigsaw technique on teaching literary genres. Educational Research and Reviews, 5(8), 439.

Huang, Y.M., Liao, Y.W., Huang, S.H., and Chen, H.C., 2014, A Jigsaw-based Cooperative Learning Approach to Improve Learning Outcomes for Mobile Situated Learning. Journal of Educational Technology \& Society, 17(1).

Huysamen, G.K., 1993, Methodology for social and behavioral sciences. (Halfweghuis: Southern Book Publishers).

Johnson, D.W., and Johnson, R.T., 2009, An educational psychology success story: Social interdependence theory and cooperative learning. Educational Researcher, 38(5), 365-379.

Karacop, A., 2017, The Effects of Using Jigsaw Method Based on Cooperative Learning Model in the Undergraduate Science Laboratory Practices. Universal Journal of Educational Research, 5(3), 420-434.

Lan, W., and Skoog, G., 2003, The relationship between high school students' motivational and metacognitive factors in science learning and their science achievement. Unpublished manuscript. Texas Tech University.

Lantolf, J.P., Thorne, S.L., and Poehner, M.E., 2015, Sociocultural theory and second language development. Theories in second language acquisition: An introduction, pp.207-226.

Lord, T.,2001, 101 reasons for using cooperative learning in biology teaching. The American Biology Teacher, 63 (1), 30-38.

Lukito, A., 2018, Effectiveness of Cooperative Learning Instructional Tools With Predict-Observe-Explain Strategy on the Topic of Cuboid and Cube Volume. In Journal of Physics: Conference Series (Vol. 947, No. 1, p. 012052). IOP Publishing.

Mashile, E. O., 2002, Learning Area Didactics: Teaching Natural Sciences. Tutorial Letter 501. Pretoria, South Africa.

Melihan, U., and Sirri, A., 2011, The effect of cooperative learning method on the students' success and recall levels of the 8th-grade students learning in permutation and probability subject. Journal of Kirsehir Education Faculty, 12, 1-16.

Mji, A., and Makgato, M., 2006, Factors associated with high school learners' poor performance: a spotlight on mathematics and physical science. South African Journal of Education, 26(2), 253-266.

Morgan, D.L., 2007, Paradigms lost and pragmatism regained methodological implications of combining qualitative and quantitative methods. Journal of Mixed Methods Research, 1(1), 48-76.

Parr, R., 2007, Improving science instruction through effective group interactions. Science Scope, (3), 21-23.

Sarah, M. W., and Cassidy, J., 2006. Cooperative learning in elementary school classrooms. Education Psychology, 393, 1-5.

Shadish, W.R., Cook, T.D., and Campbell, D.T., 2002. Construct validity and external validity: Experimental and quasi-experimental designs for generalized causal inference (Wadsworth: Cengage Learning).

Shimazoe, J., and Aldrich, H., 2010, Group work can be gratifying: Understanding and overcoming resistance to cooperative learning. College Teaching, 58(2), 52-57

Slavin, R.E., 2015, Cooperative learning in elementary schools. Education 3-13, 43(1), pp.5-14.

Van Dat, T., and Ramon, L., 2012, The Effects of Jigsaw Learning on Students' Attitudes in a Vietnamese Higher Education Classroom. International Journal of Higher Education, 1 (2): 9.

Vygotsky, L. S., 1978, Mind in society (Cambridge, MA: Harvard University Press).

Weinburgh, M., 1995, Gender differences in student attitudes toward science: A meta-analysis of the literature from 1970 to 1991. Journal of Research in Science Teaching, 32(4), 387-398. 
Sakyiwaa Danso and Emmanuel Mushayikwa / The Use Of Cooperative Instructional Strategies.......

Yang, D., and Zheng, H., 2010, "Research on the Framework of New College English Teaching Mode Integrating Cooperative and Autonomous Learning in the Network Multimedia Environment." In Proceedings of 2nd International Conference on Education Technology and Computer (ICETC), Shanghai, 3, 256-V3-259.

Zakaria, E., and Iksan, Z, 2007, Promoting Cooperative Learning in Science and Mathematics Education: A Malaysian Perspective. Eurasia Journal of Mathematics Science and Technology Education, 3(1). 35 - 39. 